\author{
Military Technical College \\ Cairo, Egypt
}

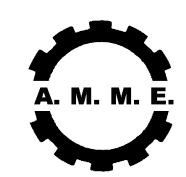

$12^{\text {th }}$ International Conference

on Applied Mechanics and

Mechanical Engineering (AMME)

\title{
WINDING ANGLE EFFECT ON FRATURE BEHAVIOR OF COMPOSITE TUBES UNDER DIFFERENT LOADING CONDITIONS
}

\author{
El-Wahab ${ }^{*}$ M. M., El-Soaly ${ }^{* *}$ E. E., El-Kader ${ }^{* * *}$ M. S., Daken ${ }^{* * *}$ M. H.
}

\begin{abstract}
Glass-fibers/plastic tubes are increasingly used in industrial environments where their strength, low weight, and corrosion resistance make them competitive with other materials. Filament winding process provides a mean of producing fiber-reinforced tubes in which the direction of fibers is closely controlled to give very high strength in preferred direction.

The aim of this work is to investigate the effect of winding angle and number of layers on burst behavior of filament wound tubes manufactured by circumferential winding process. The tubes were tested to failure under longitudinal, hoop, and biaxial loading. Filament wound tubes was fabricated using E-glass-fibers/polyester at winding angles ranging from $35^{\circ}$ to $85^{\circ}$ and number of layers 8 and 14 .

The results of internal pressure hoop test showed a significant rise in the hoop burst stress and initial modulus with increasing winding angle, while the strain to failure decreased. The high winding angle tubes, $60^{\circ}$ and above, failed by catastrophic fiber fracture. Tubes with lower winding angle were characterized by "Initial failure" associated by longitudinal resin cracking that lead to a subsequent degradation in tube modulus. The uses of rubber liner during tests lead to a significant increase in maximum stress and strain to failure.

The elastic properties were measured in longitudinal and hoop directions and a stress/strain response was obtained for each tube. The results were found to be consistent with the current theories for filament wound angle ply composites.
\end{abstract}

\section{NOMENCLATURE}

$E_{1}, E_{2}$ Young's modulus in the longitudinal (fiber) and transverse direction, $E_{f}, E_{m}$ Young's modulus of fiber and matrix, $G_{12}$ In-plane shear modulus, $G_{m}, G_{f}$ Shear modulus of matrix and fiber, $\mathrm{V}$ Volume fraction, . Strain in the longitudinal and transverse direction, Filament winding angle, $1_{12}$ Major Poisson's ratio, 1, 2 Tensile stress in the longitudinal and transverse direction.
$\mathrm{E}_{1}$
Young's modulus in the longitudinal (fiber) direction
$\mathrm{E}_{2}$
Young's modulus in the transverse direction
$E_{f}$
Young's modulus of fiber
$E_{m}$
Young's modulus of matrix 


\section{ANALYSIS ofS TRESSES AND STRAINS IN FILAMENT WOUND TUBES}

An understanding of the mechanisms of deformation and failure of composite materials requires knowledgeof the stresses and strains, which act parallel and transverse to the fibers. This is a complex problem in filament wound tubes because the material has a layer structure in which each layer is elastically and micro structurally anisotropy. The tubes used in this work consist of 8 and 14-layers at fiber angles of to the tube axis.

Puck [1] has derived expressions for the stresses and strains in each lamina when the laminate is subjected to biaxial stress. These equations, which are given below, can be applied to helically wound tubes if it is assumed that the ratio of the radius of the tube to the wall thickness is large and that plane stress conditions exist.

$$
\begin{aligned}
\mathrm{E}_{1} & =\mathrm{E}_{\mathrm{f}} \cdot \mathrm{V}_{\mathrm{f}}+\mathrm{E}_{\mathrm{m}} \cdot \mathrm{V}_{\mathrm{m}} \\
G_{12} & =\frac{G_{m}\left(1+0.6 V_{f}^{0.5}\right)}{\left(1-V_{f}\right)^{1.25}+V_{f}\left(G_{m} / G_{f}\right)} \\
\mathrm{E}_{2} & =\frac{\mathrm{E}_{\mathrm{m}}^{0}\left(1+0.85 \cdot \mathrm{V}_{\mathrm{f}}^{2}\right)}{\left(1-\mathrm{V}_{\mathrm{f}}\right)^{1.25}+\mathrm{V}_{\mathrm{f}} \cdot\left(\mathrm{E}_{\mathrm{m}}^{0} / \mathrm{E}_{\mathrm{f}}\right)} \\
G_{m} & =\frac{E_{m}}{2 \cdot\left(1+v_{m}\right)} \\
G_{f} & =\frac{E_{f}}{2 \cdot\left(1+v_{f}\right)} \\
\mathrm{E}_{\mathrm{m}}^{0} & =\frac{\mathrm{E}_{\mathrm{m}}}{\left(1-v_{\mathrm{m}}^{2}\right)} \\
v_{12} & =v_{f} \cdot V_{f}+v_{m} \cdot V_{m} \\
v_{21} & =v_{12} \cdot\left(\mathrm{E}_{2} / \mathrm{E}_{1}\right)
\end{aligned}
$$

Puck's equations for calculating the stresses and strains in a balanced angle ply composite with elastic symmetry to the center plane are:

$$
\begin{aligned}
& \sigma_{1}=\frac{1}{\mathrm{~N}_{\sigma}}\left\{\left[1-(1-2 \mathrm{AR}) \sin ^{2} 2 \phi\right]\left(\sigma_{\mathrm{A}}+\sigma_{\mathrm{H}}\right)+\cos 2 \phi\left(\sigma_{\mathrm{A}}-\sigma_{\mathrm{H}}\right)\right\} \\
& \left.\sigma_{2}=\frac{1}{\mathrm{~N}_{\sigma}}\left\{1-(1-2 \mathrm{AP}) \sin ^{2} 2 \phi\right]\left(\sigma_{\mathrm{A}}+\sigma_{\mathrm{H}}\right)-\cos 2 \phi\left(\sigma_{\mathrm{A}}-\sigma_{\mathrm{H}}\right)\right\} \\
& \tau_{12}= \pm \frac{1}{N_{\sigma}} A\left[J \cos 2 \phi\left(\sigma_{A}+\sigma_{H}\right)-B\left(\sigma_{A}-\sigma_{H}\right)\right] \sin 2 \phi
\end{aligned}
$$




$$
\begin{aligned}
& \left.\varepsilon_{1}=\frac{1}{\mathrm{E}_{1} \mathrm{~N}_{\sigma}}\left\{(\mathrm{AF}-\mathrm{M}) \sin ^{2} 2 \phi+\mathrm{M}\right]\left(\sigma_{\mathrm{A}}+\sigma_{\mathrm{H}}\right)+\mathrm{P} \cos 2 \phi\left(\sigma_{\mathrm{A}}-\sigma_{\mathrm{H}}\right)\right\} \\
& \varepsilon_{1}=\frac{1}{\mathrm{E}_{2} \mathrm{~N}_{\sigma}}\left\{\left((\mathrm{AF}-\mathrm{Q}) \sin ^{2} 2 \phi+\mathrm{Q}\right]\left(\sigma_{\mathrm{A}}+\sigma_{\mathrm{H}}\right)-\mathrm{R} \cos 2 \phi\left(\sigma_{\mathrm{A}}-\sigma_{\mathrm{H}}\right)\right\} \\
& \gamma_{12}=\mp \frac{1}{E_{1} N_{\sigma}} A\left[J \cos 2 \phi\left(\sigma_{A}+\sigma_{H}\right)-B\left(\sigma_{A}-\sigma_{H}\right)\right] \sin 2 \phi \\
& \sigma_{A}=\frac{1}{E_{1} N_{\sigma}}\left[(A F-D) \sin ^{2} 2 \phi\left(\sigma_{A}+\sigma_{H}\right)+(H-J \cos 2 \phi) \sigma_{A}-L \sigma_{H}\right] \\
& \sigma_{H}=\frac{1}{E_{1} N_{\sigma}}\left[(A F-D) \sin ^{2} 2 \phi\left(\sigma_{A}+\sigma_{H}\right)+(H+J \cos 2 \phi) \sigma_{H}-L \sigma_{A}\right]
\end{aligned}
$$

Where: $N_{\sigma}=2\left[1-(1-A B) \sin ^{2} 2 \phi\right], A=\frac{G_{12}}{E_{1}}, \mathrm{~B}=\frac{\mathrm{E}_{1}}{\mathrm{E}_{2}}+1+2 v_{12}$, $\mathrm{D}=0.5\left(\frac{\mathrm{E}_{1}}{\mathrm{E}_{2}}+1-2 v_{12}\right), \mathrm{F}=2\left(\frac{\mathrm{E}_{1}}{\mathrm{E}_{2}}-v_{12}^{2}\right), H=\frac{E_{1}}{E_{2}}+1, \mathrm{~J}=\frac{\mathrm{E}_{1}}{\mathrm{E}_{2}}-1, \mathrm{~L}=2 v_{12}$, $\mathrm{M}=1-\mathrm{v}_{12}, \mathrm{P}=1+\mathrm{v}_{12}$ $\mathrm{Q}=\frac{\mathrm{E}_{1}}{\mathrm{E}_{2}}-\mathrm{v}_{12}, \mathrm{R}=\frac{\mathrm{E}_{1}}{\mathrm{E}_{2}}+\mathrm{v}_{12}$

\section{EXPERIMENTAL WORK}

\subsection{Materials}

The Arab Company for developed materials of Egypt manufactured all the tubes used in this investigation by Filament winding. UNIX 52,600 Tex E-glass fiber roving and polyester resin type 77440 SIROPOL systems were utilized to make the tubes.

\subsection{Manufacture of Tubular Test Specimens}

The filament-winding machine, which is used in this experimental work, is a horizontal winding machine type. This winding machine is similar to the turret lathe machine, which consists mainly of a headstock and a carriage. The fabrication procedure of composite tubes consists mainly of four basic steps: preparation of mandrel, Preparation of resinous material, application of the fiber and matrix material to the surface of the prepared mandrel and proper cure of the composite material. 


\section{Preparation of mandrel}

The cylindrical mandrel preparation involves the application to the mandrel of wax for easy removal of tube after curing, appropriate separator (thin polyethylene) to preclude adhesion between the composite tube and mandrel, thin layer of surface mat for smooth internal surface of tube.

\section{Preparation of resinous material}

The structural pipe polyester resin, type (SIROPOL 77440) was used for preparing FRP pipes. The polyester resin was thoroughly mixed with $6 \%$ cobalt Naphthenate at a level of $0.2 \%$. Then just prior to use, $1.5 \%$ of Methyl-Ethyl -Ketones (MEK) peroxide was added. This mixture (resin) considered being the binder material or the manifold of the fibers. This matrix poured in the carriage tank for wetting of fiber roving during winding process.

\section{Application of the fiber and matrix materials to the surface of the prepared mandrel.}

The fiber roving is drawn from their rolls to the mandrel via the carriage in order to be wetted with the resinous material during the winding operation. A steel rod was put in the carriage tank to ensure that all fibers were impressed in the resin and a steel hand roller is used when the fibers were wrapped on the mandrel. This was to ensure even distribution of the matrix and released extra matrix.

\section{Proper curing of tubes}

Curing of tubes occurred by two heaters mounted above the mandrel, which maintained temperature at $100^{\circ} \mathrm{C}$ for 2 hours. The mandrel was then withdrawn and the tube was post cured in room temperature.

\subsection{Fiber Weight Fraction Determination}

This test was performed at the laboratory of the Arab Company for developed materials (ACDM). It was carried out by burning three specimens of known weight taken from each pipe in a special electric furnace equipped with suction ventilation. Three burning periods each of $45 \mathrm{~min}$ at the temperature of $600^{\circ} \mathrm{C}$ were sufficient to burn completely the polyester resin and leave the glass fiber roving unburned. Then by weighing the remainder roving, it was easy to determine the fiber weight fraction for each specimen. Table (1) shows the results of this test. 
Table 1. Mean Fiber weight fraction test results for 8 and 14-layer tube specimens

\begin{tabular}{|c|c|c|c|c|c|}
\hline $\begin{array}{c}\text { Winding } \\
\text { Angle } \\
(\mathbf{~})\end{array}$ & $\begin{array}{c}\text { No. of } \\
\text { Layers }\end{array}$ & $\begin{array}{c}\text { Initial } \\
\text { Weight } \\
\text { (gm) }\end{array}$ & $\begin{array}{c}\text { Polyest } \\
\text { er } \\
\text { Weight } \\
\text { (gm) }\end{array}$ & $\begin{array}{c}\text { Polyester } \\
\text { Weight } \\
\text { Fraction (\%) }\end{array}$ & $\begin{array}{c}\text { Fiber } \\
\text { Weight } \\
\text { Fraction } \\
\text { (\%) }\end{array}$ \\
\hline $35^{\circ}$ & 8 & 8.82 & 5.82 & 65.93 & 34.06 \\
\hline $45^{0}$ & 8 & 8.39 & 5.31 & 63.39 & 36.59 \\
\hline $60^{0}$ & 8 & 8.27 & 5.41 & 65.36 & 34.83 \\
\hline $75^{\circ}$ & 8 & 8.08 & 5.41 & 66.8 & 33.16 \\
\hline $85^{0}$ & 8 & 8.12 & 5.13 & 63.06 & 36.93 \\
\hline $35^{0}$ & 14 & 11.92 & 7.09 & 59.16 & 40.82 \\
\hline $45^{0}$ & 14 & 14.17 & 8.66 & 61.37 & 38.61 \\
\hline $60^{0}$ & 14 & 13.28 & 7.55 & 56.91 & 43.08 \\
\hline $75^{0}$ & 14 & 11.83 & 7.60 & 64.24 & 35.75 \\
\hline $85^{0}$ & 14 & 7.9 & 4.59 & 58.59 & 41.39 \\
\hline
\end{tabular}

\subsection{Internal Pressure Test Specimens}

Under service conditions tubes are likely to be subject to a range of stress conditions. In our experimental work we investigated two basic methods of internal pressure testing which are illustrated schematically in Fig. (1). as follows:

Mode 1 , both ends of the tubes are free to slide on seals such that the axial stress A is zero.

Mode 2, Closed-end condition so that

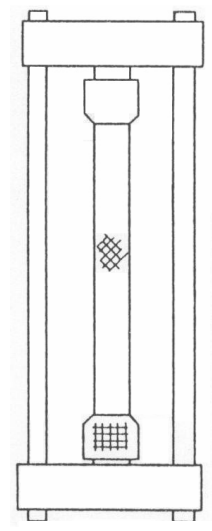

Mode 1
A for thin walled tubes.

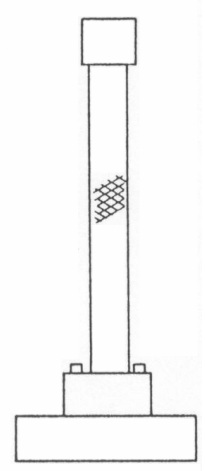

Mode 2

Fig. 1 Schematic diagram of two methods of internal pressure testing [2] 


\subsubsection{Test Specimens for Pressure Hoop Loading (Mode 1)}

The test specimens used for hoop loading were cylindrical tubes made by wet filament wound using a circumferential helical pattern. The tested winding angles were $35^{\circ}, 45^{\circ}, 60^{\circ}, 70^{\circ}$ and $85^{\circ}$ tubes with 8 and 14-layers. The resulting tubes had a fiber volume fraction ranges from $33 \%$ to $42 \%$ and a finished dimensions of $3 \mathrm{~m}$ long and $100 \mathrm{~mm}$ inner diameter, (0.9-2) $\mathrm{mm}$ wall thickness. Test specimens with a length of $300 \mathrm{~mm}$ were cut from the center 2-m to ensure that the end turn around points (where the winding carriage reversed) did not affect the gage portion of test specimens. Also, this length of specimen was chosen to be consistent with the analytical study performed by Rizzo and Vicario [3] in studying the effect of the vessel length on the behavior of the composite thin walled tubes.

The specimens are completely fitted between two steel covers connected together by four steel tie rods, as shown photographically and constructional in Fig. (2). As to the stress induced in the specimens, since all of these specimens are tie rod cylinders (bolted connection), the cylindrical wall of the specimen will be subjected to tangential stress only. Whereas, the axial stress (due to internal pressure) will be carried by the connecting rods.
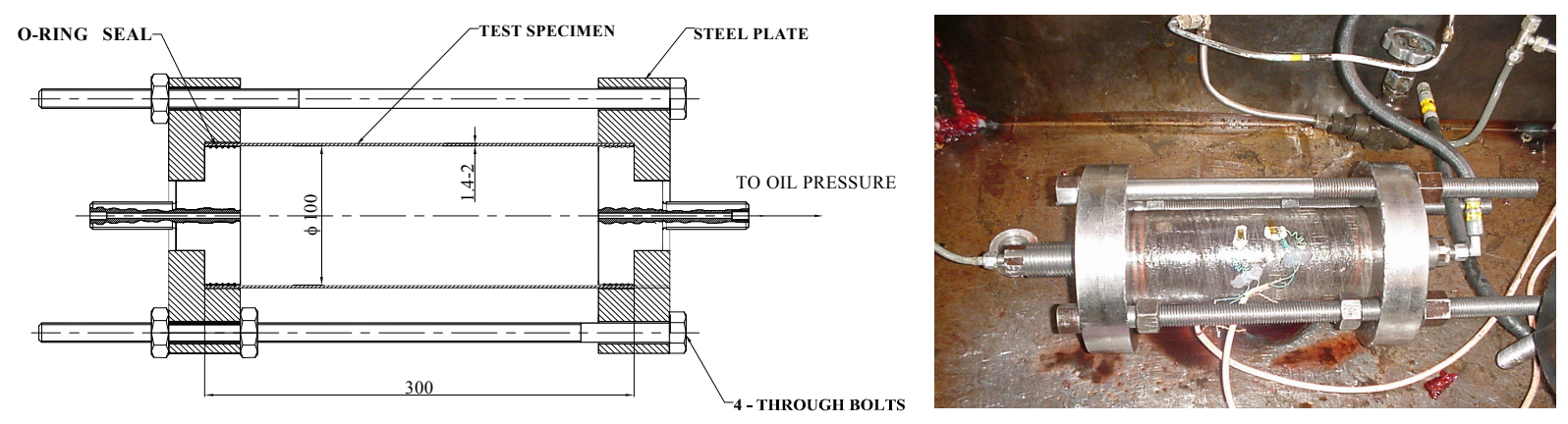

Fig. 2 Structural drawing and Post-Mortem photograph of pressure hoop loading test rig.

\subsubsection{BiaxialT est Specimens (Mode 2)}

Details of Specimen used for closed -end pressure loading are shown in Fig. (3-a). The specimens are the same as for hoop pressure loading, unless the ends had additional reinforcement which was designed to introduce the load smoothly into the gage length whilst avoid premature end failure and excessive stress concentrations. Using a chopped strand mat (CSM) and polyester resin to do this.

The specimen ends are bolted to two steel covers, as shown in Fig. (3-b). A rubber frame is used to maintain the internal pressure for a longer period thus resulting in complete fracture of specimens.

\subsection{Longitudinal Tensile Test}

This test was performed according to the British standard [4] for glass fiber reinforced pipes, by means of a tensile plate test piece. This test covers the determination of tensile properties of tubes at the longitudinal direction. The geometry 
and dimensions of the test specimens are shown in Fig. (4). Rectangular strips with

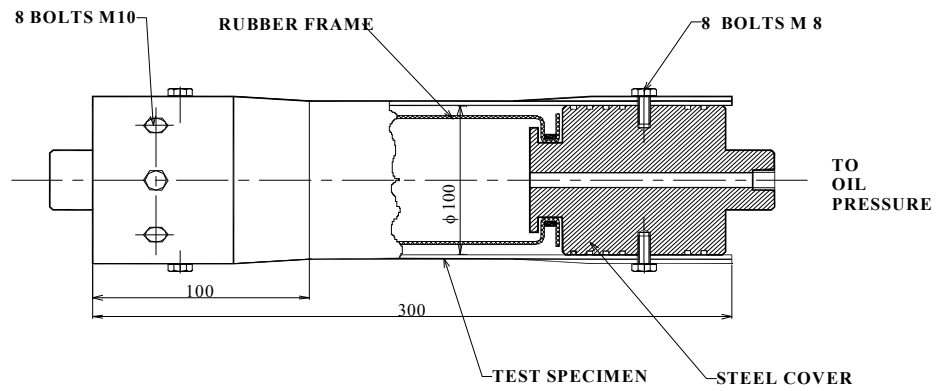

(a)

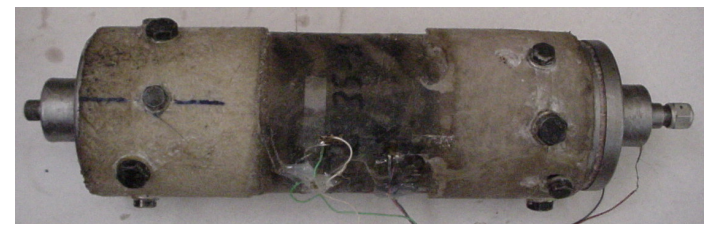

(b)

Fig. (3) Structural drawing and Post-Mortem photograph of biaxial loading test rig parallel sides of $30 \mathrm{~mm} \times 250 \mathrm{~mm}$ dimensions were cut from tubes with the longitudinal axis of the strip parallel to the longitudinal axis of tube. These strips were clamped in the grips of testing machine using a loading tab to obtain flat surface at the ends and to prevent failure of specimen at the grips. Specimen thickness was measured at nine points, and for width at three points. Thickness and width were measured using a vernier caliber of $0.01 \mathrm{~mm}$ accuracy. A $30 \mathrm{~mm}$ strain gage extensometer was attached to the center of the specimen gage length to measure longitudinal strain, while $6 \mathrm{~mm}$ long strain gage was bonded to the specimen surface to measure the axial strain.
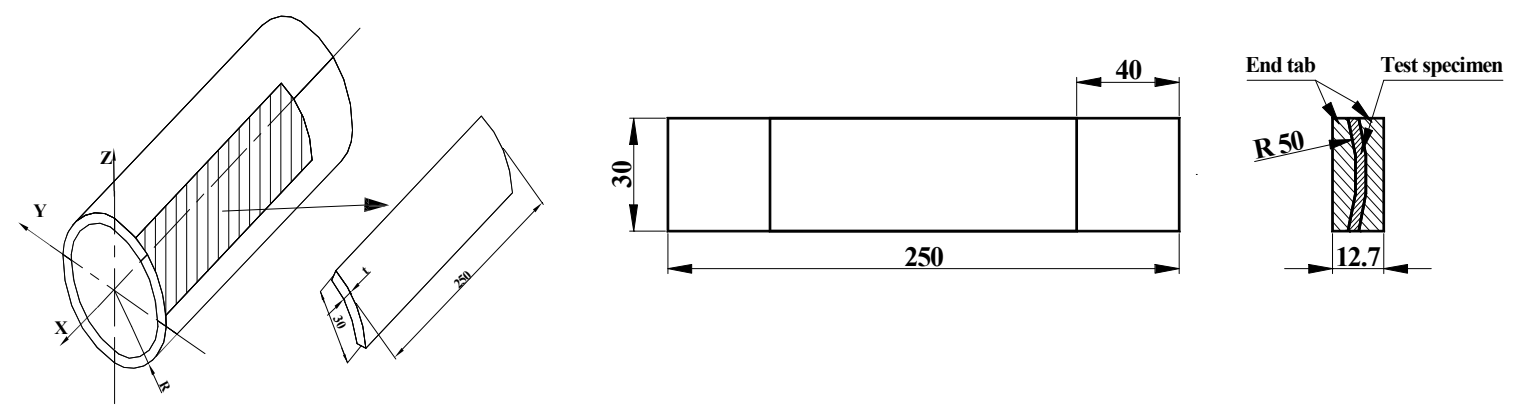

Fig. (4) Longitudinal test specimen

\subsection{Test Equipment}

\subsubsection{Internal Pressure Testing}

The internal pressure test rig used in this experimental work is shown diagrammatically in Fig. (5), and the hydraulic cylinders are shown in Fig. (6). Two hydraulic cylinders were attached between grips of MTS servo hydraulic machine model 810 to provide a controlled oil flow rate for bursting of the tested tubes during hoop and biaxial pressure test. The tubes were pressurized smoothly at a fixed rate of $200 \mathrm{MPa} / \mathrm{min}$. The main pressurization liquid was oil. It should be noted that bursting tests should always be carried out in a special purpose designed closed chamber with specimen behind a suitable safety barricade. A thin sheet of transparent plastics was used to provide good protection against sudden burst failure and oil jet during running of the test. 

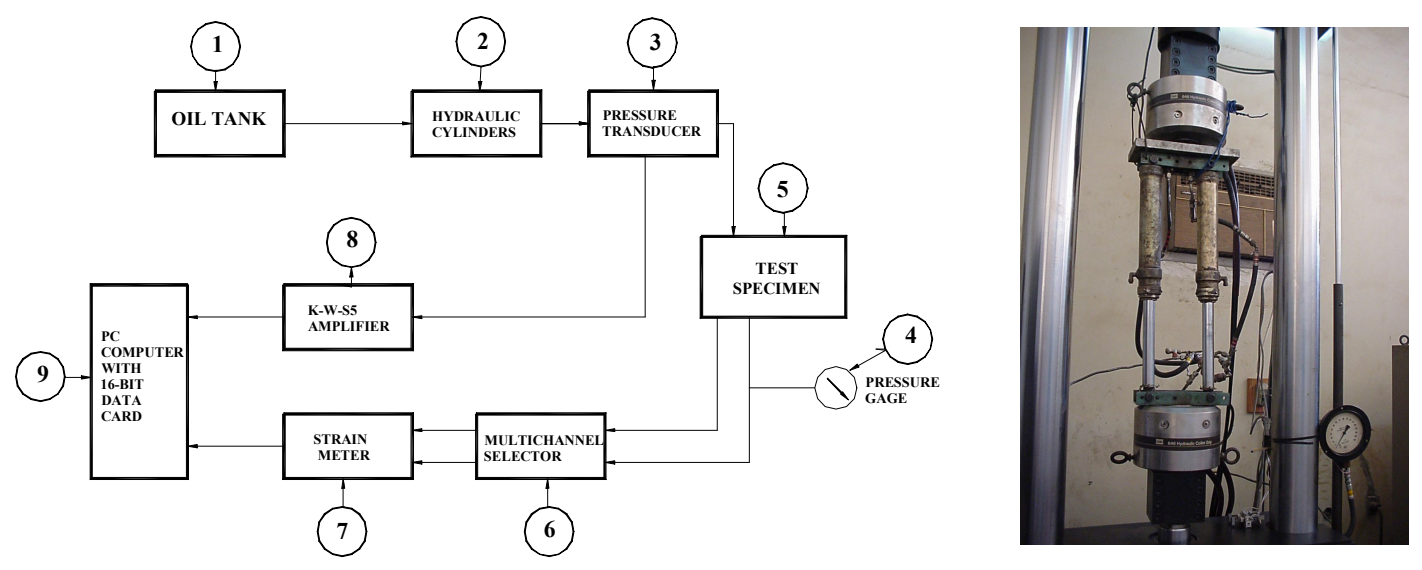

Fig. 5 Line diagram of the pressure testing equipment

Fig. 6 Hydraulic cylinders clamped between the two grips of the MTS machine circumferential and axial strain gages with length of $6 \mathrm{~mm}$ was positioned at the middle of the test section. The surface of filament wound tubes is too irregular for direct bonding of foil strain gauges. It was decided to smooth down a small area of the external surface with a fine sand paper. The area was then degreased and cleaned with acetone, and the two gauges were bonded onto this spot with X-60 adhesive. Long instrumentation connecting wires were soldered to the end tabs of strain gauges and fixed at points on surface of the tested tube by silicone. Thus ensuring that no direct mechanical loading (pulling on the wires) would be transmitted to the strain gauges.

Pressure transducer having a maximum range of $20 \mathrm{MPa}$ was inserted in the pressure line close to the tube under test to measure the internal pressure. Readings of the pressure, circumferential and axial strain gage were captured using 16-bit data acquisition card, which is connected with a personal computer (PC). Experimental results were used to obtain the following:

a) Hoop stress-strain curve at circumferential and axial direction.

b) Pressure-time and strain time curves.

c) Ultimate pressure and hoop stress.

d) Initial and secant hoop modulus.

e) Maximum hoop and axial strains.

\section{RESULTS AND DISCUSSIONS}

\subsection{InternalPressure Hoop Loading (Mode 1).}

The tubes with winding angle ranging from $35^{\circ}$ to $85^{\circ}$ and number of layers 8 and 14 were loaded under pressure hoop loading up to failure using the internal pressure test rig described in Sec. 2.4.1.

In case of winding angle $35^{\circ}$ and $45^{\circ}$, test results are obtained for lined and unlined tubes. The rubber liner allowed the internal pressure test to be continued beyond an initial "leaking level", until complete catastrophic failure occurred. 
From the measured static burst pressure values [11], the hoop burst strengths for the tested tubes were calculated and plotted against tube winding angle for 8 and 14layers Fig. (7). This shows a steady increase in the value of burst strength of the tube as the winding angle increased, which can be attributed to the small inclination of the fiber to the loading direction. It is also observed that the 14-layer tubes fail at a higher ultimate stress than 8-layer tubes. This is due to the ability of the 14-layer tubes to distribute the load carried by a failed ply to the other intact plies through inter-laminar shear stress.

The measured values of static hoop strain and axial strain at tube failure are plotted against tube winding angle in Fig. (8). This shows a unique very ductile behavior of tubes with winding angles $35^{\circ}$ and $45^{\circ}$. This finding is also confirmed by Rotem [5] and Hinton [6] for winding angle $45^{\circ}$. The large strains at fracture for $35^{\circ}$ and $45^{\circ}$ tubes are caused by substantial non-linear intra and inter-laminar shearing in the matrix. The high strain values to tube failure are limited to tube angles close to $35^{\circ}$ and $45^{\circ}$. As the winding is further increased the strain to failure value drops appreciably and levels off at a failure strain value of about 10250 strain.

During the internal hoop pressure test for tubes with winding angles $35^{\circ}$ and $45^{\circ}$, the first evidence of damage occurred as a fine jet of oil. This jet is due to formation of transverse crack parallel to the axis of tubes. As the pressure increases, the number of cracks increases and leakage rate increases before actual fiber breakage takes place. The presence of a rubber liner clearly has a marked influence on tube performance, leading to appreciable increase of ultimate strength and strain to failure, as shown in Figs. (7) and (8).

Typical measured hoop stress versus hoop and axial strain curves for the different winding angles are shown in Fig. (9). Superimposed on each of these figures are predictions based on the classical lamination theory.

The tubes with winding angle $60^{\circ}$ and up exhibit linear stress-strain relation up to final failure, while tubes with winding angles $35^{\circ}$ and $45^{\circ}$ have non-linear stressstrain relation. In all cases, the axial strain was negative and the hoop strain positive. Comparison of the experimental data with the prediction of lamination theory showed good agreement for this mode of testing. The initial slopes of stress versus strain obtained from experiment are similar to those produced by classical lamination theory. However, at larger strains the experimental results deviated from the theoretical curves because the lamination theory is a linear elastic prediction and therefore does not take into account failures that might occurs in the layer. Generally speaking, lamination theory gave reasonable predictions.

\section{Effect of liner}

The stress/strain response for lined tube specimens with winding angles $35^{\circ}$ and $45^{0}$ was linear/elastic at small strain values followed by a large region of non-linear elasto-plastic deformation. The linear/elastic response is maintained until matrix cracking occurs, which causes loss of tube circumferential and axial moduli. Without the presence of a liner, catastrophic leaking occurred and the test cannot be completed due to high leaking rate. Inspection of the outside surface revealed the 
presence of longitudinal cracks parallel to the axis of tubes. For the lined tubes, the onset of leaking was suppressed and distortion of the cross-section (into an elliptical shape) occurred as a result of extensive transverse cracking.

\subsection{Biaxial Pressure Loading (Mode 2).}

From the measured static burst pressure values, the hoop burst strength for the tested tubes were calculated and plotted against tube winding angle for 8 and 14-layers, Fig. (10). It can be concluded that the optimum winding angle for closed ended biaxial loading cylindrical tubes lies between $45^{\circ}$ and $60^{\circ}$. Many investigators showed that the optimum winding angle defined by the relation:

tan

if the tube is internally pressurized with a ratio of circumferential to axial stress of 2:1 In addition, it can be seen that the failure stresses for 14-layer tubes with winding angles $75^{\circ}$ and $85^{\circ}$ are slightly lower than for 8-layer tubes, Fig. (10). This behavior is due to failure of the two winding angle in the axial direction and the matrix is the dominant factor affecting this failure. Since the fiber volume fraction for 14-layer tubes is slightly greater than for 8-layer tubes, this increase in fiber volume fraction weakens the composite in the transverse direction. This was also found by Mahmoud [7].

The measured values of static hoop strain and axial strain at tube failure are plotted against tube winding angle in Fig. (11). Like the pressure hoop loading the tubes with winding angle $35^{\circ}$ and $45^{\circ}$ shows a unique very ductile behavior.

Typical hoop stress-hoop strain and hoop stress-axial strain curves are shown in Figs. (12) to (14) for all winding angles. All tubes showed an initial linear elastic stress/strain response. The slopes increased with increasing winding angle, where as slopes decreased with winding angle and were negative for winding angles $35^{\circ}$ and $45^{\circ}$. These results are consistent with those of previous investigations $[6,8,5$, $9,10]$.

\subsection{Stresses and strains in filament wound tubes}

Using the elastic properties of the fiber and matrix materials used in production of tested filament wound tubes, the stress and strain ratios in each lamina obtained using the equations derived by puck as described in Sec.3.4 Values of the stress ratio $\left(\begin{array}{ll}H\end{array}\right)$ and $H$ ) and strain ratios $\left.\left[H^{H} / E_{2}\right)\right]$ and were computed using MathCAD program. The variation of the stress ratios and strain ratios with winding angle are shown graphically for hoop and biaxial pressure loading tests in Figs. (15) to (18).

A comparison between the variation of the predicted hoop and axial strains with winding angle in both loading conditions showed identical trend to those obtained experimentally. 


\subsection{Longitudinal Tensile Test Results}

The mechanical properties of all tubes tested in the longitudinal direction are presented in Fig. (19) and (20). $35^{\circ}$ winding angle specimens resist more longitudinal stress than other winding angles due to small inclination angle of fibers to the loading direction. For longitudinal strain, like the pressure hoop loading the tubes with winding angle $35^{\circ}$ and $45^{\circ}$ show a unique very ductile behavior.

The experimental stress/strain relations for 8 and 14-layer tubes with different winding angles are shown in Fig. (21), along with the theoretical predictions using the classical lamination theory. With the $75^{\circ}$ and $85^{\circ}$ winding angles, the stress/strain curve was linear up to the maximum load achieved. The curves for the remainder of the tubes were initially linear. Non-linearity occurred in both axial and hoop direction with $35^{\circ}$ and $45^{\circ}$ winding angle. The $60^{\circ}$ winding angle showed

changes to non-linear behavior in the axial direction only. Comparison of the experimental data with the prediction of lamination theory showed very good agreement for this mode of testing.

\section{CONCLUSIONS}

The experimental work presented here has been devoted to investigating the effect of winding angle and number of layers on fracture behavior of glass/polyester tubes under longitudinal, hoop and axial loading. The investigation yields the following conclusions:

1- The burst pressure and the hoop modulus of the tubes increase with winding angle and number of layers. Strain to failure value is highest for the $35^{\circ}$ and $45^{\circ}$ tubes (reaches 30000 strain), dropping appreciably as the winding angle increases and eventually leveling off at a value of 10250 strain during internal pressure hoop loading.

2- The failure mechanisms of GRP tubes depend on fiber orientation. Under hoop pressure loading, the high winding angle tubes, $60^{\circ}$ and up, failed by catastrophic fiber fracture. The lower winding angle tubes were characterized by an initial failure associated by matrix cracking and leading to catastrophic oil leakage and modulus degradation.

3- The optimum winding angle for filament wound tubes depends primarily on the state of loading. From this study, it appears that filament wound tubes should be wound at $60^{\circ}$ for biaxial pressure loading, $85^{\circ}$ for hoop pressure loading and the lowest possible angle for tensile loading.

\section{REFERENCES}

[1] Puck, A. and W., Schneider," On Failure Mechanisms and Failure Criteria of Filament-Wound Glass-Fiber/Resin Composites", Plastics and Polymers 37, pp. 33-43, (1978).

[2] Hull, D., M. J. Legg, and B. Spencer, "Failure of Glass/Polyester FilamentWound Pipe", Composites 9, No. 1, pp. 17-24, (1978). 
[3] Rizo, R. R., and Vicario, A.A," A Finite Element Analysis for stress Distribution in Gripped Tubular Specimens", ASTM STP 497, Composite Materials: Testing and Design, , pp. 68-88, (1972).

[4] British Standard: Design and Performance Requirements, Bs 5480: Part 2, (1982).

[5] Rotem, A. and Z. Hashin," Failure Modes of Angle Ply Laminates", Journal of Composite Materials, pp. 9-21, (1975).

[6] Hinton, M. J.," The elastic Prperties of Filament -Wound GRP Tubes," RARDE Technical Report 14/79, (1979).

[7] Mahmoud, S., A., "Fracture and Fatigue Behavior of Fiber-Glass/Polyester Laminates", Thesis of Ph. Dr. in Mechanical Engineering, Cairo University, (1995).

[8] Highton, J., A. B. A Deoye, P. D. Soden," Fracture Stresses for $75^{\circ}$ Degree Filament-Wound GRP Tubes Under Biaxial Loads", Journal of Strain Analysis, Vol. 20, No.3., pp. 139-151, (1985).

[9] Spencer, B. and D. Hull," Effect of Winding Angle on the Failure of FilamentWound Pipe", Composites, October 78, No. 4, pp. 163-271, (1978).

[10] Carswell, W. S. and L. Ainworth," The Behavior of Glass Filament Wound Tubes Under Internal Pressure," Inter. Conference on Composite Materials, Toronto, Canada, pp. 472-483, (1978).

[11] M. M. A. Et Wahab, E. E. El-Soaly, M. S. A. El-Kader, M. H. H. Daken, " Fatigue Behavior of Polymer-Based Fiber Composites", Thesis of Ph. Dr. in Mechanical Engineering, Military Technical College, (2002). 